\title{
INMIGRACIÓN Y MAYORAZGO: FRUSTRACIÓN DE LOS MONTANARO Y OTROS COMERCIANTES DEL LEVANTE ESPAÑOL (ALICANTE Y CARTAGENA, 1670-1730)*
}

\author{
Vicente Montojo Montojo \\ Real Academia Alfonso X el Sabio
}

\begin{abstract}
Resumen: En este texto se estudia el recurso al mayorazgo por algunos grandes comerciantes del Levante español, como el genovés Juan Bautista Montanaro, de Cartagena, y algunos otros que le precedieron, en el marco de su adopción por inmigrantes. Esta utilización de la vinculación por merced regia, que correspondió en su caso a un proceso de movilidad social ascendente mediante un ennoblecimiento que llegó a la obtención de un título nobiliario, se mostró fugaz y problemática por causa de su condición austracista, lo que impidió la aplicación del mayorazgo hasta cuarenta años después. Se recurre a la comparación con la dificultad de aplicación de otros mayorazgos de comerciantes, aunque en un contexto diferente.
\end{abstract}

Palabras clave: Historia Social, Historia Moderna, Oligarquías, Mayorazgos.

Inmigration and mayorazgo: frustration of the Montanaro and other merchants of Eastern Spain (Alicante and Cartagena, 1670-1730)

Abstract: In this text, it will be studied how mayorazgo was adopted by some prominent foreign merchants in Western Spain, like Genoese Juan Bautista Montanaro from Cartagena, and some others before him. The use of mayorazgo -by royal mercy- was linked to social mobility processes in order to obtain a nobility title, long and complex by Montanaro Austracist affiliation, postponing forty years the concession. We will compare this difficult case with others merchants mayorazgo applications but in different contexts.

Key words: Social History, Early Modern History, oligarchies, Mayorazgos.

Situarnos en un espacio fronterizo y litoral, como el Levante español en la Edad Moderna, y por lo tanto abierto a la inmigración de extranjeros, sobre todo de artesanos, artistas y comerciantes, no nos aleja de una sociedad compleja, afectada por la movilidad social (Cachón, 1989). El crecimiento demográfico tan destacado de sus ciudades portuarias se alimentó de movimientos migratorios, tanto producto de inmigración laboral (Rogles, 1984) como de exilios (Ruiz, 2005). Además de mercados laborales y de productos, estas poblaciones ofrecían oportunidades de matrimonios ventajosos, en mayor medida que en otras rurales, es decir, eran focos importantes de inserción de extranjeros, de especial relieve a finales del siglo XVII (Torres, 1998, 262). Y de hecho, la manifestación más común de la integración de los inmigrantes fue el matrimonio con nacionales. De esta forma, la inmigración podía llegar a ser una opción de movilidad social, de tendencia ascendente, pues

Data de recepció: 31 d'octubre de 2016 / Data d'acceptació: 28 de novembre de 2016.

* Trabajo financiado en el proyecto de investigación Nobilitas III por la Fundación Séneca. 
siempre se hacía con sentido de mejora, salvo que fuera forzosa. Esta inmigración, en nada comparable a la de hoy, no dejó de preocupar a las autoridades de su tiempo, ya fuera por razón de la peligrosidad que se atribuía a los desplazamientos de los moriscos granadinos, que fueron objeto de control mediante registros periódicos (Chacón, 1982; Guerrero, 2003), o por causa de la prevención que produjo la introducción de los genoveses en el gobierno municipal y la organización financiera y fiscal, ocasionadora también de vigilancia sobre sus avecindamientos a finales del siglo XVI y principios del XVII (Montojo, 1991).

No obstante, las sociedades urbanas respectivas se articulaban mediante la confluencia de diversos valores, como el carácter nobiliario de los principales o poderosos, o el de su tendencia a la perpetuación, a través de vínculos y mayorazgos, entre otros. Si hiciéramos caso a los cronistas (Cascales, por ejemplo) nos hallaríamos ante sociedades homogéneas, fueran urbanas o rurales, dominadas por el peso de sus grupos nobiliarios. Sin embargo, el favor real, el matrimonio, la riqueza y la venalidad hicieron de las élites de las ciudades marítimas grupos permeables, de tipo mosaico o mestizaje, es decir, más compuestos de personas procedentes de otros lugares. Como consecuencia, en ellas hubo una cierta tensión producida por la dificultad de mantener el equilibrio deseado por los naturales. Estos últimos fueron, como en tantos otros sitios, los primeros entre quienes destacó la tendencia a perpetuarse, mediante actuaciones de determinados fundadores de mayorazgos (Hernández, 1998), entre quienes destacaron algunos clérigos como patronos (Chacón, 1995), pero no se dio entre ellos de manera exclusiva, pues también se extendió a otros grupos.

Así, entre otros individuos, algunos grandes comerciantes fundaron mayorazgos, como determinados extranjeros, que acreditaron su condición noble y compraron oficios de regidores de los concejos o municipios. Eran, por lo tanto, inmigrantes distintos a aquellos que se considera necesitados de inserción, como pudieran ser los berberiscos del siglo XVI o los malteses del XVIII dedicados al pequeño comercio, o los caldereros y leñadores franceses, pues en el caso de los genoveses y sobre todo de los bretones eran posiblemente exiliados en razón de las guerras de religión de Francia (Ruiz, 2005), o de la revuelta de parte de la nobleza ligur, o seguidores de una tradición familiar, como la de ayudar o continuar un negocio de un familiar, o recibir una herencia.

Precisamente en este trabajo se analizan varios ejemplos de mayorazgos fundados por grandes comerciantes de Alicante y Cartagena, como medio de clarificar una tipología compleja de mayorazgos, caracterizada por su dificultosa aplicación y su frustración temporal, en un intento de integración del análisis de la familia en su contexto político y social. Como es bien sabido, el estudio del mayorazgo nos aproxima al conocimiento del sistema hereditario y de perpetuación del linaje, puesto que la regulación de éste en la recepción de la herencia transmite unas relaciones de parentesco que trasfieren el poder y la dependencia.

El mayorazgo castellano es no sólo objeto de análisis como un elemento de estudio de la movilidad social, sino también como estado social identificador de una suma de individuos que se supone que obtuvieron éxito en su trayectoria vital, un grupo selecto.

A ello contribuiría la aceptación de una relación servicial, pues su fundación se efectuaba mediante una escritura notarial específica, o por medio de una cláusula testamentaria, que en ambos casos requería previamente de una facultad de fundación, es decir, de una carta o provisión real, característica y denotativa de la gracia regia. Su establecimiento implicaba importantes efectos jurídicos sobre los sucesores del fundador, cuya herencia era distribuida de forma desigual. De esta última circunstancia derivaron frecuentes plei- 
tos, origen de numerosos árboles genealógicos y de otros muchos documentos. De aquí también la explicación de que haya importantes volúmenes de documentación de mayorazgos cuya existencia es a veces difícil de comprender en determinados archivos.

Así, a la mentalidad del mayorazgo acompañaba una cultura de conservación de los títulos de la fundación, que había que legar a la posterioridad, aunque es muy frecuente que los conozcamos a través de las actas notariales y de los procesos judiciales y no de los archivos familiares, éstos muy escasos. Los fondos familiares se caracterizan por su heterogeneidad (suelen concentrar documentos de diversas familias), por lo que se aconseja su organización atendiendo en primer lugar a la estructura familiar característica del Antiguo Régimen, ligada al mayorazgo o al solar conocido.

Este es el caso de algunas grandes casas de la alta nobleza, aquella que se formó primero a partir del parentesco regio (los Enríquez o los Manuel, por ejemplo), de las grandes mercedes enriqueñas y del valimiento o del favor real, para luego ir afianzándose a través de la concentración de patrimonio y rentas y del mayorazgo.

Esta práctica social se extendió a la pequeña nobleza, colectivo que consiguió ser reconocido como tal por el rey, sobre todo a partir del siglo XVI, en que la presión por conseguir mejores encabezamientos fiscales y servicios militares hizo que la nobleza urbana exigiera el reconocimiento de su exención mediante padrones de hidalgos y pleitos ante los tribunales de justicia.

Pero también los comerciantes extranjeros (los italianos o los franceses de Levante, por ejemplo, pero no en exclusiva) consiguieron ver reconocida su nobleza, si la tenían, o adquirirla, a lo que ayudaba el asiento crediticio, y pudieron asimismo fundar mayorazgos con los que perpetuar su linaje.

Así nos consta para Alicante y Cartagena, que fueron sedes de importantes mayorazgos, como en tantas otras poblaciones de España, si recordamos a modo de ejemplo los que incluyeron los señoríos de Aigües, Ares, Bañeres, Busot (Francisco Bosch Martínez de Vera, marqués del Bosch) y Benasau (Jacinto Forner, barón de Finestrat), u Hoya Morena y Cúllar-Baza, éstos dos últimos obtenidos por vecinos de Cartagena a pesar de que su número fue escaso, en comparación con otras ciudades del reino de Murcia (Montojo, 1993). No obstante, a mediados del siglo XVIII fray Pedro Manuel Ortega declaró que Cartagena "se halla ilustrada con mucha nobleza, algunos títulos y señoríos" (1994, 141). Era ésta una afirmación que se ha de entender teniendo en cuenta que algunos oficiales de la Armada, principalmente, habían obtenido títulos nobiliarios en premio a sus servicios en las guerras de Italia del reinado de Felipe V. Sin embargo, a diferencia de los títulos, los mayorazgos de Cartagena tenían una mayor antigüedad (siglos XVI y XVII) y, como lo hacían en otros lugares, arrastraban las contradicciones en que pudieron incurrir sus fundadores, además de algunos otros problemas anejos.

Si en el siglo XVI las fundaciones se hicieron sobre todo de pequeños vínculos, por lo tanto de menor importancia en cuanto a su entidad y, en lo que se refiere a sus bienes, por parte de grandes propietarios de tierras y ganado, fue en el XVII cuando se alcanzó una mayor complejidad, por la composición en parte comerciante de las oligarquías en Alicante y Cartagena (Montojo, 2010), no de forma pacífica, sino con dificultades. 


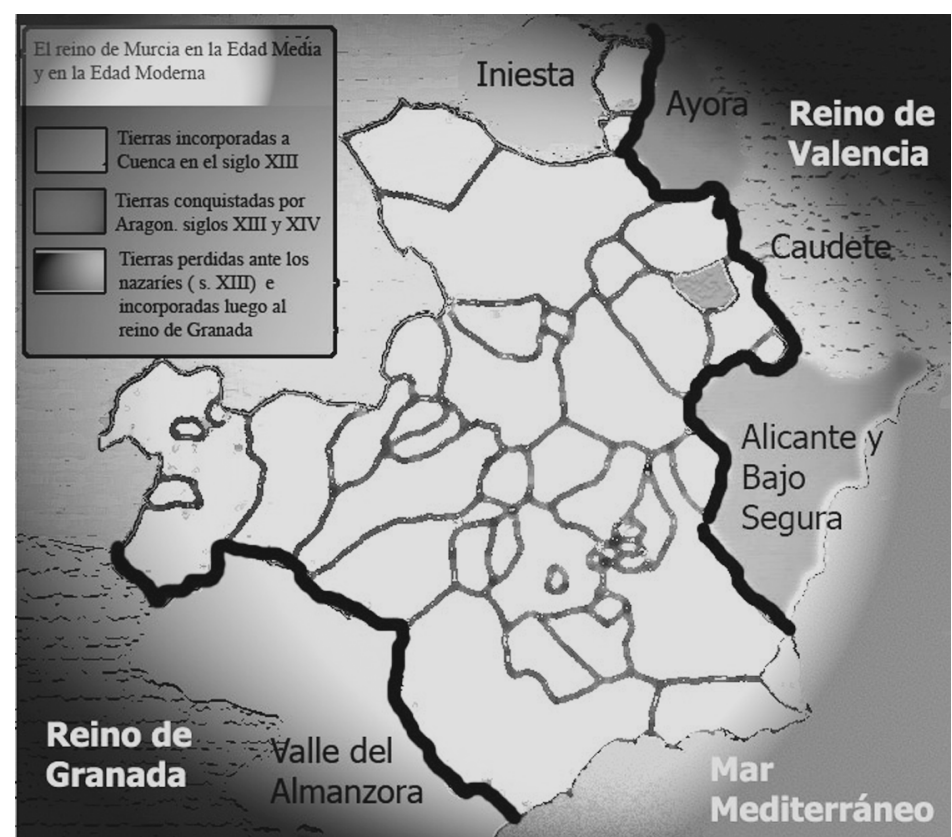

Mapa del Reino de Murcia y la Bailía de Alicante y Gobernación de Orihuela. Cedido por Julio D. Muñoz Rodríguez.

\section{LOS MONTANARO ENTRE LOS COMERCIANTES GENOVESES DE ALICANTE Y CARTAGENA}

La fundación de un mayorazgo por uno de estos comerciantes la conocemos por un pleito que sostuvieron sus nietos 50 años después (1759-1766) de otorgar su testamento (1710). Es el caso de Juan Bautista Montanaro, poseedor del apellido genovés de algunos individuos que formaron parte del comercio de Alicante y Cartagena en el siglo XVII y el primer decenio del XVIII. Juan Bautista Montanaro fue hijo de Jaime Montanaro, natural de Génova, gobernador de Varasi (Génova), y de Jerónima de Oca, también genovesa. Antes, Juan Andrea Montanaro residió en Alicante ${ }^{1}$ temporalmente, aunque desconozco si fue pariente de los de Cartagena, de quienes se documenta su actividad 40 años después, pero es posiblemente una muestra de la atracción de las ciudades portuarias del Levante español para los genoveses durante la Edad Moderna, puesto que constituyeron núcleos importantes de comerciantes en España.

Juan Bautista Montanaro vivió una época muy difícil para el comercio de Cartagena (en sentido de grupo social), como fue el reinado de Carlos II, con cuatro guerras con

\footnotetext{
${ }^{1}$ En 1628-1630 Cosme Micón, de Madrid, pleiteó contra Miguel Ángel Montanaro, mercader residente, por 9.550 reales de deuda en letra de cambio. La Audiencia dio la razón a Micón y la quitó al batle: Arxiu del Regne de Valencia (ARV), Audiencia, parte III, leg. 3099.
} 
Francia entre 1667, fecha del inicio de la primera, la de la Devolución, y 1697, en que terminó la última, la de los Nueve años o Liga de Augsburgo, en la cual se perdieron varios barcos que transportaban mercancías suyas, hundidos por los franceses. Además, presenció la conocida como epidemia de peste de Cartagena (1677) y varias manipulaciones monetarias (1680 y 1686), que debieron también afectar negativamente. Todo ello incidió en una fuerte presión fiscal difícil de afrontar salvo con el contrabando ${ }^{2}$, pues ni siquiera los comerciantes de Cartagena controlaban el arrendamiento de las contribuciones fiscales, a pesar de que lo intentaron ${ }^{3}$.

A diferencia de un comercio de Alicante mucho más destacado gracias a su exención fiscal, el de Cartagena sólo pudo beneficiarse de la instalación de la escuadra de galeras

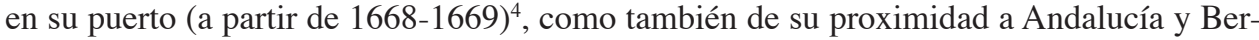
bería, que le permitieron buenas relaciones con Cádiz, Málaga y Orán. Como en Alicante, también en Cartagena se dio una importante inmigración de franceses (sobre todo provenzales y bearneses), a partir de 1660, que pudo mantenerse a pesar de las guerras, pues fue librada de la expulsión a cambio de contribuir con la farda (Poitreneau, 1976; Montojo/ Maestre, 2005).

Pero tras cinco años de paz (1697-1702), la Guerra de Sucesión española (1702-1715) interrumpió un periodo de recuperación económica y social.

Juan Bautista Montanaro, como muchos otros genoveses que se instalaron en Cartagena desde finales del XVI, podía contar en la ciudad con el apoyo de una red mercantil hispanoitaliana, formada por descendientes de genoveses y venecianos, como los Imperial, Pelerán, Prebe y Digueri (él casó en cuarto matrimonio con Concepción Montenegro Imperial, perteneciente a estas familias originarias de Génova pero naturalizadas), con propiedades en Cúllar, Galera y Huéscar, poblaciones del reino de Granada. En ellas habían destacado algunos comerciantes muy vinculados a la exportación de lana por Alicante y Cartagena con destino a Génova y Venecia (en ésta muy bien relacionados) y a la importación de manufacturas italianas (Montojo/Maestre, 2000).

Es muy poco lo que sabemos de sus matrimonios anteriores, casi todos con italianas, pero el segundo, con Septimia Ansaldo, le unió con otra familia de comerciantes de Alicante y Cartagena, cuyo hermano, Juan Bautista Ansaldo, pudo participar en su negocio. ${ }^{5}$

Sus acreedores eran en 1710 Juan Bautista Rocién (Madrid), Guillermo Druche (Londres), Juan del Poyo (Cartagena), José Rusi (Alicante), Oliveri y Médicis (Lisboa), Juan Leonardo Smeloc (Mallorca), Francisco Campión (Venecia), José Reyse (Venecia), Aurelio Resonico (Venecia), Diego Dollife (Londres), Juan Bautista Marción (Génova), Sres. Cárregas de Juan Bta. (parientes, Génova), Juan Catá y Compañía (Pablo Dalmases, Bar-

${ }^{2}$ Los hombres de negocios de Cartagena pidieron que se redujera a la mitad el impuesto concejil del real por quintal de barrilla exportada, a causa de que el recaudador de rentas reales les pedía que se ajustasen a pagar una cantidad moderada por lo mismo: Archivo Municipal de Cartagena (AMC), Ac.Cap. 18-1-1687, f. 179. El recaudador municipal denunció que introducían grandes cantidades de barrilla en sus almacenes sin registrarla (AMC, Ac.Cap. 6-9-1687).

3 Para ello en 1690 se asociaron Montanaro, Nicolás Fábrega, Miguel Peragalo, Juan Bta. Ansaldo, Pedro Pablo Merizano, Mateo Rizo y Tomás Moore (Velasco, 2001, p. 422).

4 A ello contribuyó la posición de España, amenazada en el Estrecho de Gibraltar por la presencia inglesa en Tánger desde 1662 (Sánchez Belén, 2000).

5 Casó con Florentina Peragalo, según el testamento de su hijo Antonio Ansaldo: AHPM, Not. $5523 / 697$. 
celona) ${ }^{6}$ y Jerónimo Masio (Arensano), es decir, de una gran variedad de procedencias dentro de Europa Occidental; y sus deudores lo fueron César Colombo (sobrino, Génova) y 37 vecinos de Cartagena, Murcia y su campo y Totana ${ }^{7}$. Esta distribución de acreedores manifestó una composición definida por los países aliados en la Guerra de Sucesión de España contrarios a Felipe V de Borbón.

Pudo acumular un gran patrimonio, como diversas fincas rústicas en el Campo de las Salinas (Orihuela y Almoradí, comprada por 750 doblones), donde predominó el marqués de Rafal (Bernabé, 2006), 2 en Sucina (el Canal, con molino, y la Casa Blanca, por valor de 10.200 pesos) y 2 en la huerta de Cartagena (el Jardín), una en el campo (la del Albujón, por 4.000 pesos), y 7 casas en Cartagena (2 las donó al Hospital de Caridad, de cuya hermandad fue su tercer hermano mayor ${ }^{8}$, y otras 2 para la fundación de un Convento de Santa Florentina, de agustinas recoletas, que no se llegó a realizar).

Sin embargo, los resultados de toda esta actividad tuvieron efectos muy dispares según la época: así, a sus hijos mayores (Antonio $\mathrm{M}^{\mathrm{a}}$ y Nicolás Montanaro) pudo darles 30.000 ducados a cada uno, por legítima paterna y materna; a José y a Agustín (solteros cuando testó) 13.000 ducados de legítima materna y 5.000 de la paterna a cada uno; y a Rosalía y Jerónima, hijas del tercer matrimonio, que tenían derecho nada más que a la dote de su madre (no hubo gananciales), sólo 6.000 pesos en total a cada una. Hubo, por lo tanto, grandes diferencias en la distribución hereditaria, que se hizo progresivamente más reducida, beneficiándose sólo los dos mayores.

\section{EL ENTRONQUE CON LOS SUCESORES DEL MAYORAZGO DE VICENTE IMPERIAL (1638)}

La familia de la cuarta mujer de Juan Bautista Montanaro (Concepción Montenegro Imperial) era una de las descendientes del clan genovés Digueri-Imperial-Pelerán-Prebe, uno de los más importantes del comercio de Cartagena desde finales del siglo XVI y de la corporación municipal a mediados del XVII, y de Alicante. Sin embargo, a finales de este siglo estaba experimentando una sensible reducción, a causa del agotamiento biológico de unas familias en que había predominado una estrategia matrimonial endogámica muy acusada.

Un cuñado de Juan Bautista Prebe, Vicente Imperial Jobardo fundó en 1638 un mayorazgo, que fue también problemático. En este caso porque su hijo mayor, Vicente Imperial Digueri, aunque casado con una mujer de familia no consanguínea (Josefa Aroca Fajardo, de Murcia), cosa excepcional en la familia Imperial Digueri, ni otros varones tuvieron descendencia directa (Francisco Imperial Digueri, casado con Tomasa Prebe, su prima, hija de Juan Bautista Prebe), salvo una de sus hijas, Margarita Imperial Digueri.

Pero ésta contrajo dos matrimonios, el primero con Juan Antonio Digueri, un miembro de su parentela, natural de Génova. El matrimonio se vio interrumpido, no por la muerte de Digueri, sino porque éste tuvo que huir a Génova llevándose a su hijo Ambrosio Ignacio Di-

\footnotetext{
${ }^{6}$ Fue titular de la Compañía Pablo Dalmases, Catá y Piria, que tuvo varios negocios con los Montanaro: Monter, 17??, 11. J.B. Montanaro apoderó a Pablo Dalmases y Ros: AHPM, Not. 5377/131, 6.9.1691.

7 Archivo Histórico Nacional (AHN, Madrid), Consejo de Castilla (C), Ejecutoria n. 5.059.

8 También su hijo Antonio $\mathrm{M}^{\mathrm{a}}$ Montanaro participó en alguna reunión y Nicolás Montanaro, su segundogénito, le sucedió como hermano mayor desde 1706 hasta 1721: Ferrándiz, 1981; Rubio, 1977, 12-23.
} 
gueri Imperial, tras haber dado muerte al proveedor de armadas y fronteras, una de las autoridades militares de Cartagena. Cuando Digueri se disponía a marcharse, Margarita Imperial concertó, quizá previo divorcio, un segundo matrimonio, con Rocho o Roque de Montenegro, también natural de Génova, alcalde mayor de Cartagena (lo fue primero de Murcia y después auditor de las galeras de España). Los Digueri quedaron marcados por este suceso y otros como personas violentas.

A la muerte de Vicente Imperial Digueri, sin hijos, pasó el derecho de sucesión del mayorazgo fundado por su padre a una rama lateral, la de Margarita Imperial Digueri, pero hubo pleito entre Francisco Montenegro Imperial, hijo del segundo matrimonio, y Juan Antonio Ignacio Digueri Campión ${ }^{9}$, hijo de Ambrosio Ignacio Digueri Imperial ${ }^{10}$ y nieto de Juan Antonio Digueri y de Margarita Imperial Digueri, quien reclamó la sucesión del mayorazgo para sí y los suyos (1687). Alegó para ello que la enmienda hecha en el mayorazgo, según Montenegro a favor de los hijos del segundo matrimonio, era falsa, pues cuando fundaron el mayorazgo (22-5-1638) no estaba casada Margarita Imperial, que lo hizo 6 meses después (3-11-1638): “porque a esto (el que viva en Génova) dio causa el que el dicho marido primero que tuvo la dicha doña Margarita fue genovés y muy inquieto, que cometió diversos delitos que fueron causa para que se ausentase y fuese a Génova, y habiéndose despachado un juez pesquisidor de orden del Real Consejo contra él, por haber matado al proveedor de armadas y fronteras, se destruyeron todos los bienes de la dicha doña Margarita y, reconociendo el fundador que se había vuelto a Génova, trató de excluirlo de la sucesión y a sus descendientes, y preferir a los del segundo matrimonio de la dicha su hija, cuando ya había casado en segundo matrimonio doña Margarita, que crió en su casa a su nieto, don Manuel, al que tuvo especial afecto, y además don Juan Antonio se llevó a su hijo don Ambrosio Ignacio...".

Pero según la otra parte: "no se prueba que haya quedado descendencia legítima que sea capaz de la sucesión de este mayorazgo, porque aunque se quiere dar a entender que la parte contraria es hijo del dicho don Ambrosio Ignacio y doña María Verónica, no se comprueba en la partida de bautismo que se ha presentado entre las de sus hijos, lo uno porque no conviene en los nombres, porque no es todo uno don Ambrosio Ignacio o don Ignacio sólo, y este Ignacio, marido de doña Verónica, puede ser otro distinto de don Ambrosio bautizado en Cartagena, por la diversidad que hay de los nombres".

Juan Antonio Digueri Campión alegó que su abuelo se llevó a su padre cuando se trataba el segundo matrimonio de Margarita Imperial, para facilitarlo.

Finalmente, la sentencia de 6-3-1693 dispuso que Francisco de Montenegro Prebe no había probado y que Vicente Juan Antonio Digueri era el sucesor legítimo. A pesar de ello, Digueri siguió protestando, porque no pudo cobrar las costas puesto que sus bienes en Cartagena eran vinculados y Montenegro tenía mucho poder, gracias a sus parientes, entre quienes estaría Tomás Pelerán Digueri o Prebe ${ }^{11}$. Años después (1706) Francisco Montenegro Im-

9 Fue bautizado en Génova el 19-2-1661 con el nombre de Juan Antonio Ignacio Francisco María, hijo de Ignacio Diguero y Verónica Campión, siendo compadres Nicolás Campión y Leonor Magdalena Castillona. Tuvo por lo menos 2 hijos: Ignacio Jacinto Juan Esteban, bautizado el 15-1-1684, siendo comadre Bárbara Campiona; y Jacinto Ignacio, bautizado el 26-7-1686: Archivo de la Real Chancillería de Granada (ARChG), cabina 3/caja 861/pieza 6: pleito de los Imperial en 1687-1691/1819.

10 Bautizado el 12-2-1629, siendo compadre Vicente Imperial, regidor (idem).

11 En 1672 se alineó con Juan Carlos Tacón, Luis García de Cáceres Jara, Alonso de la Jara Molina, Juan García Alcaraz y Andrés García de Cáceres en un pleito contra Gaspar Enríquez, Pedro Francisco 


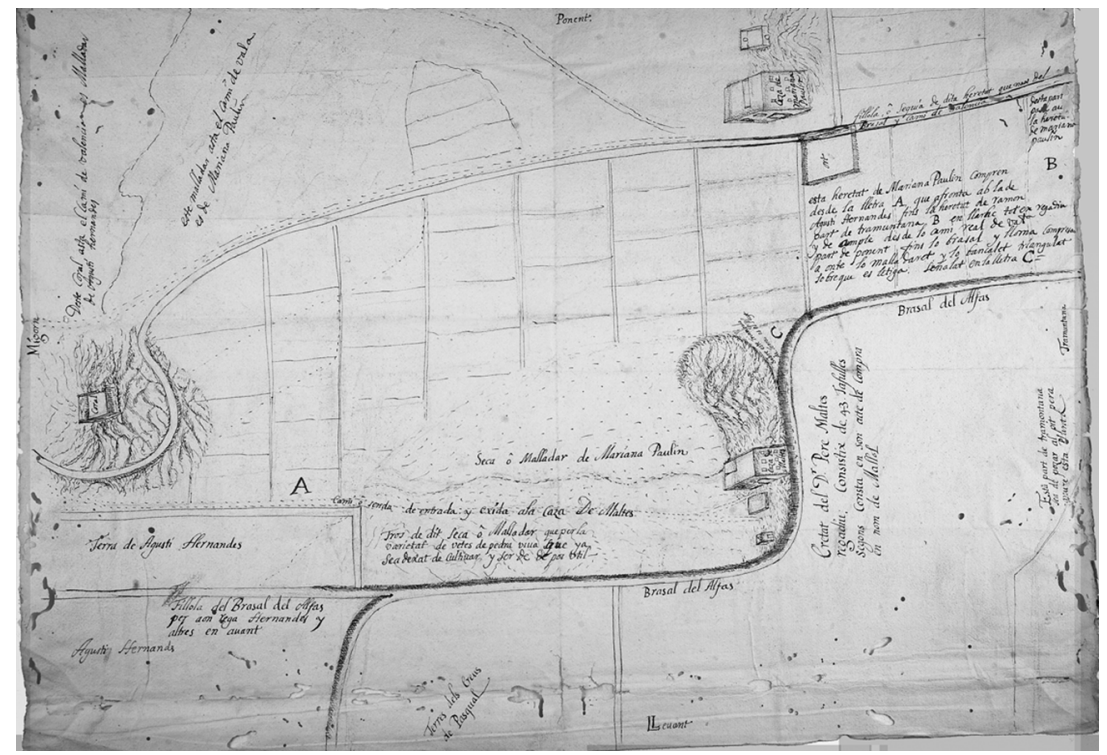

Plano de la huerta de Alicante con expresión de la hacienda de Mariana Paulin, hija del caballero inglés Guillermo Paulin (siglo XVII). Archivo del Reino de Valencia, fondo Audiencia Real de Valencia.

perial, señor de Cúllar, se quejó de que Juan Antonio Digueri Campión no había reparado los bienes del mayorazgo y pidió que se le embargase, porque se consideraba sucesor. A lo que Digueri contestó que tenía 3 hijos y que Francisco Montenegro Imperial no era sucesor.

Por lo tanto, en 1693 el mayorazgo de Vicente Imperial Jobardo pasó a un Digueri de Génova, mientras que unos años después (hacia 1706) Francisco Montenegro, partidario de Felipe V, heredó el mayorazgo de Juan Bautista Prebe, que incluía el señorío de Cúllar, después de ser ostentado por Tomás Pelerán Fajardo desde 1675.

Si Juan Bautista Montanaro pudo quizá pretender el acceder mediante su cuarto matrimonio a la sucesión del mayorazgo de Vicente Imperial Jobardo, mucho más acertado estuvo Francisco Montenegro, con el de Prebe, además de que acertó en seguir la causa de Felipe V.

\section{EL ACCESO DE JUAN BAUTISTA MONTANARO A UN TÍTULO NOBILIARIO: UN ASCENSO FUGAZ}

Por otra parte, a pesar de su riqueza, no obtuvo Juan Bautista Montanaro ninguna merced ni ningún oficio real, tanto de Carlos II como de Felipe V. En el último cuarto del si-

Rato, Nicolás Garro de Cáceres, Francisco González de Rivera, Sebastián del Hoyo, Antonio Martínez Fortún, José González de Rivera y Francisco Bermúdez, regidores, por haber estos últimos nombrado compromisarios para recibir al marqués de los Vélez sin convocarles a los primeros al cabildo extraordinario en que fueron elegidos (ARChG, cabina 3/caja 754/n.12). 
glo XVII, las necesidades de socorro militar a Orán y la ayuda al frente catalán fueron oportunidades de relaciones de servicios al rey y su corte que podían ser ocasión de obtener concesiones ventajosas, de las que se beneficiaron algunos regidores de Murcia, con títulos nobiliarios, y de Lorca y Cartagena, con títulos de caballeros de Santiago o alguna otra orden militar y con oficios militares distintivos. Así, a la jubilación de Alonso de la Jara y Molina, caballero de Santiago, como sargento mayor de Cartagena (1690), fue promovido Tomás Pelerán Fajardo (Muñoz, 2003ª 196/66), como también unos pocos a caballeros de órdenes militares ${ }^{12}$.

Montanaro llegó a ser regidor del Ayuntamiento ${ }^{13}$, pero sus mandas testamentarias (disponiendo la fundación de un convento y donaciones al Hospital de Caridad, del que fue hermano mayor) indican un cierto arraigo en la ciudad. También su hijo Antonio María Montanaro fue hermano mayor de otra cofradía, la de Jesús Nazareno, en la que entonces predominaban los comerciantes y mercaderes (Montojo/Maestre, 1999, 42-3).

Pero tras el dominio austracista de Cartagena, en 1706, al que colaboraron Montanaro y otros comerciantes genoveses (Guillamón/Muñoz, 2006), aquél recibió como gracia del pretendiente rey Carlos III, archiduque de Austria, el título de marqués de Huércal Overa, con el señorío de la población, las tercias reales, más la torre de los Alcázares (Murcia) con sus aljibes y 200 fanegas de tierra labradiza.

La concesión del título de marqués de Huércal Overa, junto con diferentes bienes, y la de facultad para fundar mayorazgo por el archiduque Carlos de Austria, estando Montanaro exiliado en Barcelona, se fundamentaron en sus servicios a la causa austracista, que debieron ser relevantes: recuérdese que Cartagena fue entregada por sus propias autoridades a la armada angloholandesa (junio 1706), hasta que a finales del mismo año fue tomada por las tropas borbónicas.

El título nobiliario fue el primero que se entregó a un vecino de Cartagena, como también el de conde de Pozo Nuevo a don Luis Panés Figueroa (Maestre, 2011; como he dicho antes, las guerras de Italia de Felipe V fueron la ocasión para que otros los consiguieran: marqueses del Bloqueo, la Victoria, Cáceres, Camachos, Campo Nubla), a diferencia de Murcia, donde cuatro personas los recibieron durante el reinado de Carlos II (Muñoz, 2003b, 207-13). De no ser por su exilio, Juan Bautista Montanaro se hubiera convertido en la personalidad más destacada de la nobleza cartagenera. Esto explica la insistencia con la que Montenegro solicitó un título: fueron varias cartas las que envió a Grimaldo y a Belluga con este fin, pero entre las razones que pudo haber en su no concesión debió estar la oposición a promocionar a un personaje difícil como debía ser Montenegro (disputas diferentes con otros regidores así lo demuestran), y la inconveniencia de convertirlo en el centro de poder de una sociedad postbélica como la de Cartagena (Muñoz, 2014, 285 y 300).

Todo ello lo transmitió a su viuda y vinculado a su hijo mayor, Antonio María Montanaro, con la esperanza de favorecerle. Sin embargo su decisión fracasó, pues su hijo mayor fue también austracista, como su padre, y tuvo que exiliarse a Viena, junto con su mujer e hijos, donde murió (1740). En cambio Nicolás Montanaro y los demás hijos e hijas menores de Juan Bautista Montanaro (José, Agustín, Rosalía y Jerónima) permanecieron en Cartagena. En una Cartagena que se sumó tan ardientemente al austracismo, Nicolás

\footnotetext{
12 Miguel Clemente Benzal y Alonso Hernández en 1675 y 1691: Muñoz, 2003b, 208 y 223.

13 Lo compró a Josefa Rodríguez viuda de Jerónimo Llana: AHN, E ${ }^{\circ}$ Carlos 3ㅜ nº. 997. Girón, 2012, 237.
} 
Montanaro se adaptó a la nueva situación borbónica y fue utilizado por Belluga en diferentes ocasiones. Así como Montenegro no consiguió el título, Montanaro fue recuperado para el filipismo en una estrategia de equilibrio político que benefició en última instancia a Belluga. Los que se quedaron en Cartagena, donde se repartieron la herencia de su padre, evitaron temporalmente el mayorazgo, cuya aplicación se dilató casi cuarenta años, hasta que un hijo de Antonio María Montanaro, José Montanaro Aguado, regresó a España tras la paz de Viena (1725) -de aquí que se sacara una copia del testamento y fundación del mayorazgo en 1730- y reclamó ser legítimo sucesor del mayorazgo, lo que le reconoció la justicia en 1742, tras pleito ante la Real Chancillería de Granada, derecho que luego se le revocó (1743) y finalmente se le entregó su patrimonio (bienes por valor de 402.394 reales, en 1748). Pero fallecido José Montanaro Aguado (1759) sin descendencia masculina, Joaquín Montanaro Fábrega, hijo del mencionado Nicolás Montanaro, reclamó la sucesión del mayorazgo, a lo que se opuso una hija de José Montanaro Aguado, a cuya demanda se añadió la de $\mathrm{M}^{\mathrm{a}}$ Inés Piescht por su hijo Agustín $\mathrm{M}^{\mathrm{a}}$ Montanaro Piescht, nieto de Antonio $\mathrm{M}^{\mathrm{a}}$ Montanaro ${ }^{14}$.

Por entonces (1759-1760) Rosalía Montanaro, hija de Juan Bautista, protestó de que se le había producido agravio en la adjudicación de bienes libres que se le hizo, solicitando que se la igualase en bienes de la calidad que habían recibido los demás, pero sin poner en duda la subsistencia del mayorazgo en que fue reintegrado José Montanaro Aguado en 1748.

La intervención de $\mathrm{M}^{\mathrm{a}}$ Inés Piescht, marquesa viuda de Montanaro, como madre del marqués Agustín $\mathbf{M}^{\mathrm{a}}$ Montanaro Piescht, residentes en Trieste (entonces Austria, su base naval), complicó mucho más las cosas, pues tras enviudar de Antonio Ma José Montanaro (casados en 1730), teniente de navío de la armada de Austria, debió contar con pocos apoyos en España, ya que apoderó para el pleito a Jaime de Abadal, otro exiliado español residente en Viena, quien nombró procurador a Salvador del Castillo, vecino de Alcantarilla.

Aunque el mayorazgo fue fundado por un gran comerciante de Cartagena, es decir, un hombre de negocios, Juan Bautista Montanaro se casó con italianas y en un cuarto matrimonio con una descendiente de italianos (Concepción Montenegro Imperial), pero con este último matrimonio emparentó con familias importantes de Cartagena (su pariente Miguel Antonio Montanaro estaba casado con Manuela Corvari Prebe) y Murcia (Pellicer Saavedra y Aroca Fajardo).

En las dificultades para la aplicación del mayorazgo y el título concurrieron circunstancias políticas. En primer lugar, la concesión del título de marqués de Huércal Overa por el archiduque Carlos de Austria se hizo en Barcelona, a causa de su exilio por austracista (1710). Como miembro de los vencidos en la Guerra de Sucesión española, en este caso de carácter civil, el título nobiliario apenas tuvo vigencia en España, pero los sucesores austriacos de Montanaro sí pudieron ostentarlo en Viena y en Trieste.

Su mayorazgo incluía un gran patrimonio inmueble, reunido durante muchos años por un hombre de negocios muy bien relacionado en Alicante, Génova y Venecia. De hecho la fundación del mayorazgo pudo ser contemplada por Juan Bautista Montanaro como una

${ }^{14}$ Antonio $\mathrm{M}^{\mathrm{a}}$ Montanaro financió la reparación y publicación de unas imágenes religiosas en Mallorca (El agravio satisfecho: Sermón de las imágenes de Cristo ... de la Virgen ... del Rosario, S. Francisco, des trozadas por los moros en Orán y rescatadas para repararlas y solicitarles veneración pública en Mallorca, Mallorca, Miguel Capó, 1711), además de pleitear con su madrastra por el título de marqués de Huércal Overa con el que figura en este impreso de la Biblioteca Nacional (VE 1449/9 y Porcones 15/21). 
estrategia económica, pues denunciando la crisis que supuso la guerra (su capital se había reducido a diez u once mil pesos) dispuso que su hijo mayor fuera invirtiéndolo en bienes del mayorazgo ${ }^{15}$. Disposición que no fue posible ejecutar, pues sólo el tratado de Viena, de paz con Austria (1725), permitió que algún hijo del exiliado volviera a España y reclamara la herencia del mayorazgo, lo que no se hizo hasta 1742.

El pleito de tenuta se complicó, pues un descendiente del hijo mayor consiguió que se le restituyese el mayorazgo, pero sobre todo se alargó ante las expectativas que producía la desaparición de los herederos. Así, la muerte de José Montanaro Aguado, hijo de Antonio María Montanaro, en 1759, atrajo a los sucesores de Trieste: Agustín Antonio Ma Montanaro Pietsch, su sobrino. En el pleito se mezclaron cuestiones políticas relacionadas con la fidelidad al rey o al pretendiente, que alegaron los primeros para excusar la ejecución del mayorazgo.

Los Montanaro austracistas y exiliados fueron un ejemplo de integración de austracistas en Italia y en Viena, donde ejercieron oficios militares, como lo hizo un siglo antes el valenciano Baltasar Marradas o Marrades, que llegó a ser maestre de campo y a recibir varios señoríos y un título nobiliario que heredó su hijo natural Baltasar Marradas.

\section{CONCLUSIÓN: EL MAYORAZGO DE LOS MONTANARO A LA LUZ DE OTRAS FUNDACIONES DE COMERCIANTES DE ALICANTE Y CARTAGENA}

El de Montanaro permite una comparación con mayorazgos fundados por grandes comerciantes de Alicante, como Julio Escorcia, cuyos capítulos fundacionales fueron complejos $^{16}$, Bernardo Berardo ${ }^{17}$, Pablo Salafranca ${ }^{18}$, Juan Agustín Ansaldo ${ }^{19}$ o Francisco

15 "Declaro que habiendo puesto en poder de mi hijo don Antonio María por vía de compañía lo que constará por los libros en consideración de los contratiempos de las guerras y otros acasos por los cuales juzgo que de todo el caudal que puse en su poder sólo vendrán a quedar unos diez mil a once mil pesos, mando y quiero que dicha cantidad o la que constare quedar vaya el dicho mi hijo don Antonio poco a poco en cada un año reemplazando para irlo todo cargando a favor del mayorazgo, o que vincule en él de su hacienda lo que constare quedar debiendo de dicha compañía, que yo de mi parte desde ahora para entonces lo dejo vinculado y en este parte le cargo la conciencia por el fraude de sus descendientes y de los otros hijos míos y descendientes de ellos, llamados en la sucesión del mayorazgo, no cumpliendo lo que en esta parte dejo dispuesto" (AHN, Consejos, Ejecutoria n. 5.059).

16 Julio Escorcia casó con doña Isabel Ferrer, hija de don Luis de Próxita (conde de Almenara) y doña Isabel Sanz: Cláusulas de su testamento ante Joan de Torres, de 25-11-1628, publicado el 8-5-1632, en que dejó heredero universal a don César Escorcia: Bibl. Municipal Serrano Morales, $n^{\circ}$. 11c6797); era de 20.000 libras, al que se añadieron 850 libras en censales (6-11-1636). Sobre Próxita: Santarrufina, 2014. Un descendiente suyo, Álvaro Escorcia Ladrón i Aracil, hijo de Nicolás Escorcia Ladrón, fue sargento mayor de Alicante, coronel, maestre de campo, austracista y gobernador interino de Ibiza en 1712 y 1714 : Pradells, 1984, 65, 70-1, 204 y 265; Vidal, 2014, 187.

17 Fue agente de M. Cortizos hacia 1648 (Sanz, 2010, 7) y nombrado administrador de las salinas de La Mata y caballero de Santiago (1650). Casó con Margarita Pasqual de Ibarra, con quien fundó mayorazgo.

18 Pablo Salafranca: hijo de Bernardo Salafranca, vecino de Valencia, y hermano de Gaspar Salafranca, comerciante de Cartagena, pagador de armadas y fronteras en ella, mayordomo del Cabildo Catedralicio de Murcia. El vínculo fue aprobado el 24.6.1653 por la Audiencia: FA.140.723 (Biblioteca de Vicente del Cacho). A Pablo sucedió Tomás S.: http://dadun.unav.edu/handle/10171/30965 [Consultado: 1-12-2016]. 
Marbeuf (Giménez, 1986), y Cartagena: Fulgencio Panés (1687/1691), Vicente Imperial (1638), Juan Bautista Prebe (1633), Esteve Conrado (Montaner, 2006, 152), genoveses, Nicolás Toya Monsarrate (1676), de origen catalán, Juan del Poyo, bearnés, y Julián Junge, bretón (1600). Algunos de ellos tuvieron una difícil ejecución. Así el de Fulgencio Panés Rato, como el de Juan Bautista Montanaro, fue fundado fuera de Cartagena (en Cádiz, donde Panés era comerciante), pero sobre bienes radicados en Cartagena, Murcia y Alguazas, pues su único hijo, ilegítimo, Luis Panés Figueroa, había sido enviado a Cartagena, junto a Juan Andrés Panés, tío de Luis y socio de Fulgencio. El mayorazgo de éste se dispuso en 1691, una vez fallecido el padre (1687) y legitimado Luis, quien fue austracista y hubo de exiliarse en 1706, como tantos otros genoveses de Cartagena (Muñoz, 2014, 1548 y 270-3). Es el caso de Luis Panés Rocamora, hijo de Juan Andrea Panés y doña Blanca Rocamora y Molíns, que protagonizó una brillante carrera en la administración municipal de finales del siglo XVII y fue uno de los líderes de la Cartagena austracista, por lo que debió exiliarse en Nápoles (Muñoz, 2006).

Ciertamente, las dificultades de constitución y ejecución de los mayorazgos fueron moneda corriente, lo que acarreó una cierta dosis de frustración, sobre todo en algunos herederos. Juan Bautista Prebe fundó 2 mayorazgos, uno para el hijo mayor y otro para el segundo, pero su cumplimiento se retrasó mucho, pues debía constituirse al alcanzar una cantidad de dinero que dependía de los censos que para ello se constituyeran: los pleitos se alargaron durante años ${ }^{20}$. Otros mayorazgos, que incluyeron entre sus bienes determinados oficios municipales, como el de alguacil mayor del Ayuntamiento de Cartagena en poder de Vicente Imperial (al que iba unida la prerrogativa de voto preferente en los cabildos), fueron origen de discordias con los demás regidores de la corporación municipal. Por otra parte, la protección de hijos menores hizo que el mayorazgo se fundara con limitaciones, lo que podía sumarse a otros problemas. Por ejemplo, no sólo los herederos de Juan Bautista Montanaro eran menores de edad, salvo Antonio María y Nicolás, sino que éste casó con María Fábrega Machavelo, también de ascendencia genovesa, y tuvo participación en la actividad de la compañía de comercio de su padre y hermano mayor, pero no como socio, y cuando Cartagena fue tomada por las tropas borbónicas (noviembre 1706) hubo de dar un fuerte cantidad a los vencedores. No se trató exactamente de un donativo, sino que Cartagena, como ciudad conquistada, tuvo que pagar el consiguiente tributo por su traición. La cantidad fue negociada por Belluga, la adelantó Nicolás Montanaro y se comprometió el concejo a devolverla, teniendo que hacer a continuación grandes esfuerzos para recuperar las propiedades de su padre y cobrar las deudas que se le debían (Muñoz, 2014, 263).

Montanaro pudo aprovechar las oportunidades de compras de oficios de regidores que tuvieron los Imperial y Prebe en el reinado de Felipe IV, pues en el de Carlos II se tendió al consumo o extinción de oficios ${ }^{21}$. Pero es posible que la decisión de fundar un mayorazgo

19 "Estos Ansaldos pasaron a Cartagena, de donde vinieron a Alicante. Aquí vivieron como caballeros respetados de la nobleza. Fundaron su casa y mayorazgo": Alegación en derecho por Jusepa Bernabeu, viuda de Alejandro Forner, con Juan Agustín Ansaldo, alguacil del Santo Oficio de la Inquisición, sobre si habiendo aquella firmado de derecho en la Real Audiencia de Valencia..., 1650: IB, VII, V19, 38164.

${ }^{20}$ ARChG, cab ${ }^{\text {a } 508, ~ l e g . ~ 2025, ~ n . ~ 2, ~ 1713 ; ~ c a b ~} 3$, leg. 1057, n. 18, 1715. AHN, C, leg. 11539, n. 560, 1763-4.

21 Fue tal consumo en 1669 (AMC, Ac.Cap. 30-9-1687, folios 214-215). 


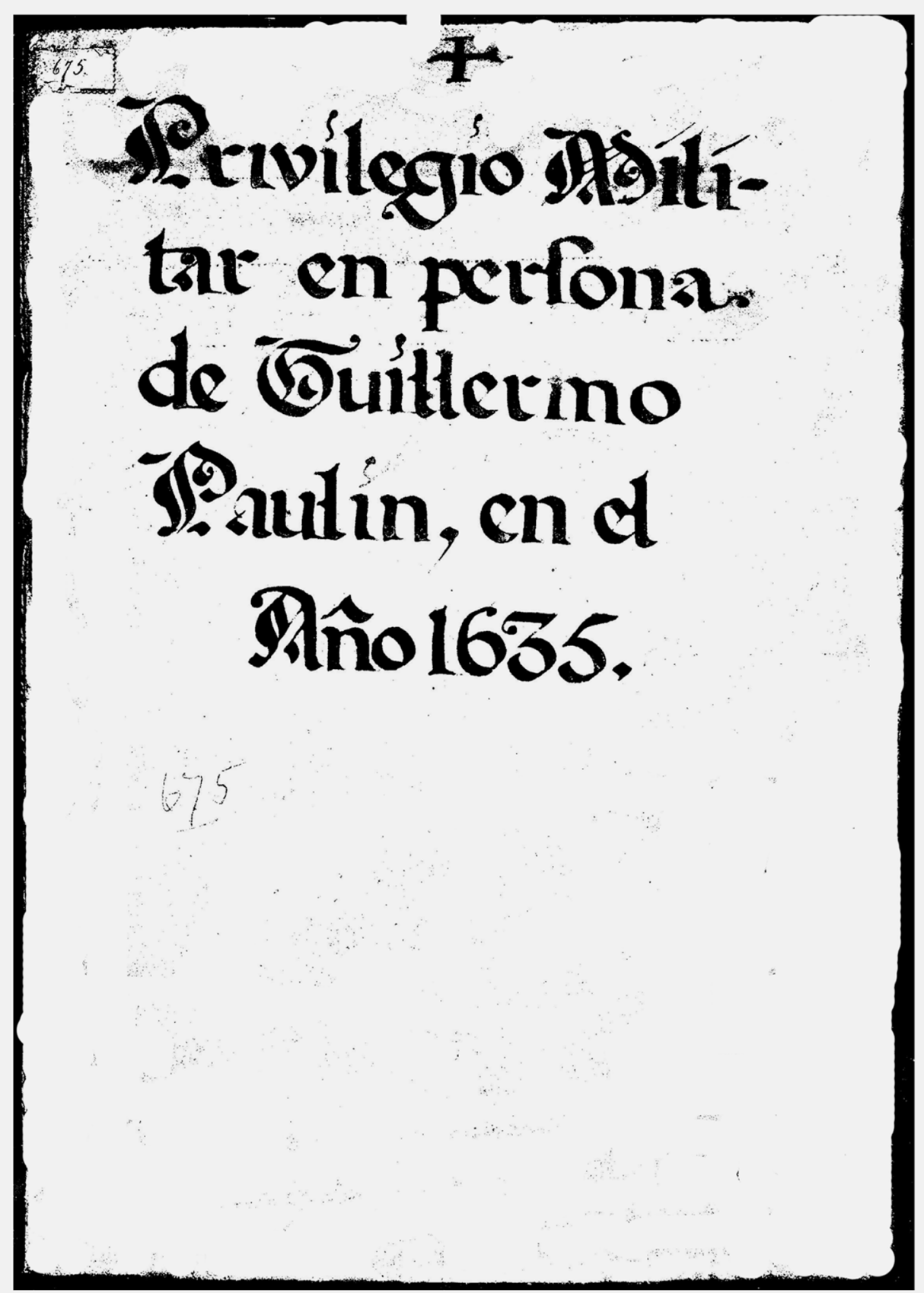

Privilegio de nobleza de Guillermo Paulin, comerciante inglés de Alicante (año 1635) cuya posesión dio Nicolás Escorcia. Foto: Biblioteca de la Universidad de Edimburgo. 


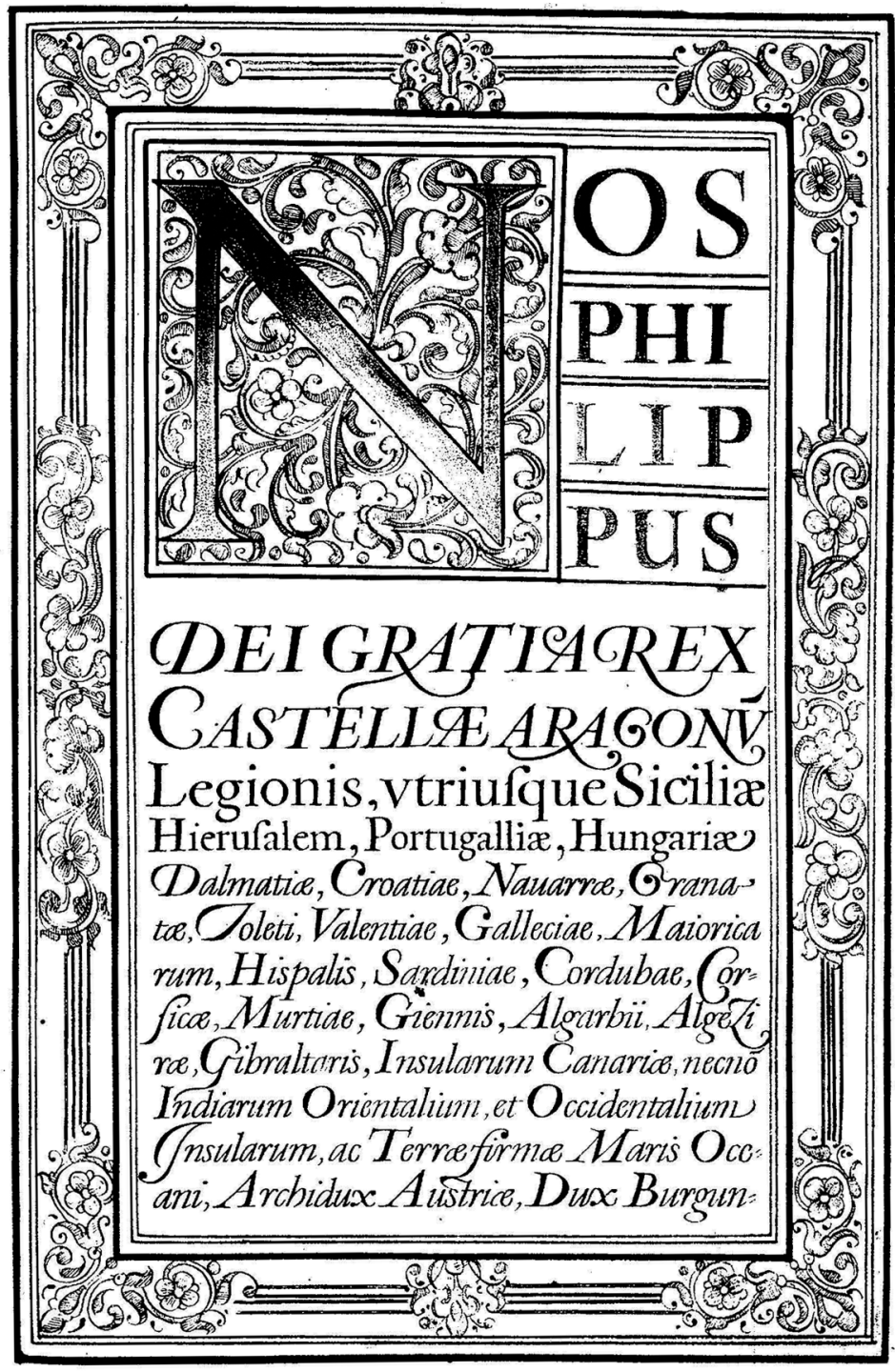


diae, Brabantiae, Mediolani, Athenarum, (O) Neopatriae, Comes Habspuroii, Flandriae, Jivo . lis, Barcinonae, Rossilionis, et Ceritaniae, Marchio Oristani,et Comes Goceani. MAGNANI= $M I$, et excelsi tunc Regis fungimur officio, quan: do subditos, etcoassallos, non solum indigenas, sede= tiam aduenas coariis honorum, gratiis, et titulis illu: Stramus; eos fiquidem quorum origo, ac nostri obsequii propensio benemeritos efficit. Quaproptercó fidcrantes laudabilia merita, et Dirtutum ornamê ta tuifidelis, ac nobis dilecti GVILIE RMI\% $P A V L I N$ oriundi à willa de Saltask ing $R e=$ gro Angliae, ac nunc vicini nostre ciuitatis. Ali= cantis in dicto Valentiae Regno, quo pro Fidei Ca tholicae obseruantia, instante deuotione, te contulisti, ot confugisti. Volentesquè obid, et tui in nos animi propensionem, ac feruitia perte coariis in rebus no bis praestita, et imponfa ergate, et successores tuos nos munificos, et liberales ostendere, in frascripto mi litiae gradu te, et eos modo infrascripto condecorandos duoximus. Quare nostris Regïs literis in morem no strae $R$ gegide. Aragonum Cancellariae expeditios datis in oppido Matriti die trigesima mensis Ianu arii proximè fluxi $\mathrm{Nobili}$ fidcli, ac dilecto nostro don Nicolao Scorcia in dicta ciuitate eAlicantios commoranti cornmissimus, quod to dictum GVI. 
LIER MVM PAVLIN nomine, etricenírí. - dictec militiae, et bonoris gradu insigniret, et decoraret. Quiguidern don $\boldsymbol{N}_{\text {icolaus }} S_{\text {corcia in }}$ sim dictae n'́e regiac commissionis te Militem armauit, militariquè cingulo decoralut, ot nobis constitit ex instrumento re cepto per Stephaintm Blanco notarium publicum se pecdicta cilutatis Alicantis die onigrssimo primo mé sis Februarii proximè fuxi. Quo circa tui GVI LIERMI PAVLIN nomine, ot pro parte fuit cticm Muiestatinostra humilitor supplicatum ot opportunum Prinilegium tibi desuper concedere, et expediri mandare dignaremur. 1 os nero peti tione tua benignè suscepta, cidemqui annuentes, ac laudantes, approbantes, rattificantes, et confirman tes huiusmodi contextu omnia, et singula oice, nomine nostris in tuif fauorem per dictum don $\mathrm{N}_{i \mathrm{c}}$

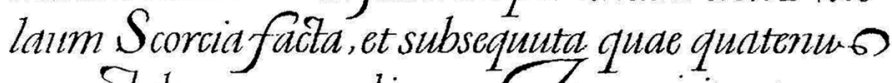
opus est de nouo concedimus. Denore igitur presen tis de nostra certa scientia Regiaque auctoritate deli beraté, et consultò tibi dicto Guilicrmo Paulin conce dimus, et clargimur, quod tu ipse, totaque proles, et posteritas tua legitima per oirilem sexum descendens tom nata quàm nasaitura deinceps sitis nomine mini, et intitulemini Milites, ot militari cingulo de $=$ corati. Possitisquè, etroaleatis deferre ensem, cal= caria, ct alia aurca ornamenta ad equestrem, siue 


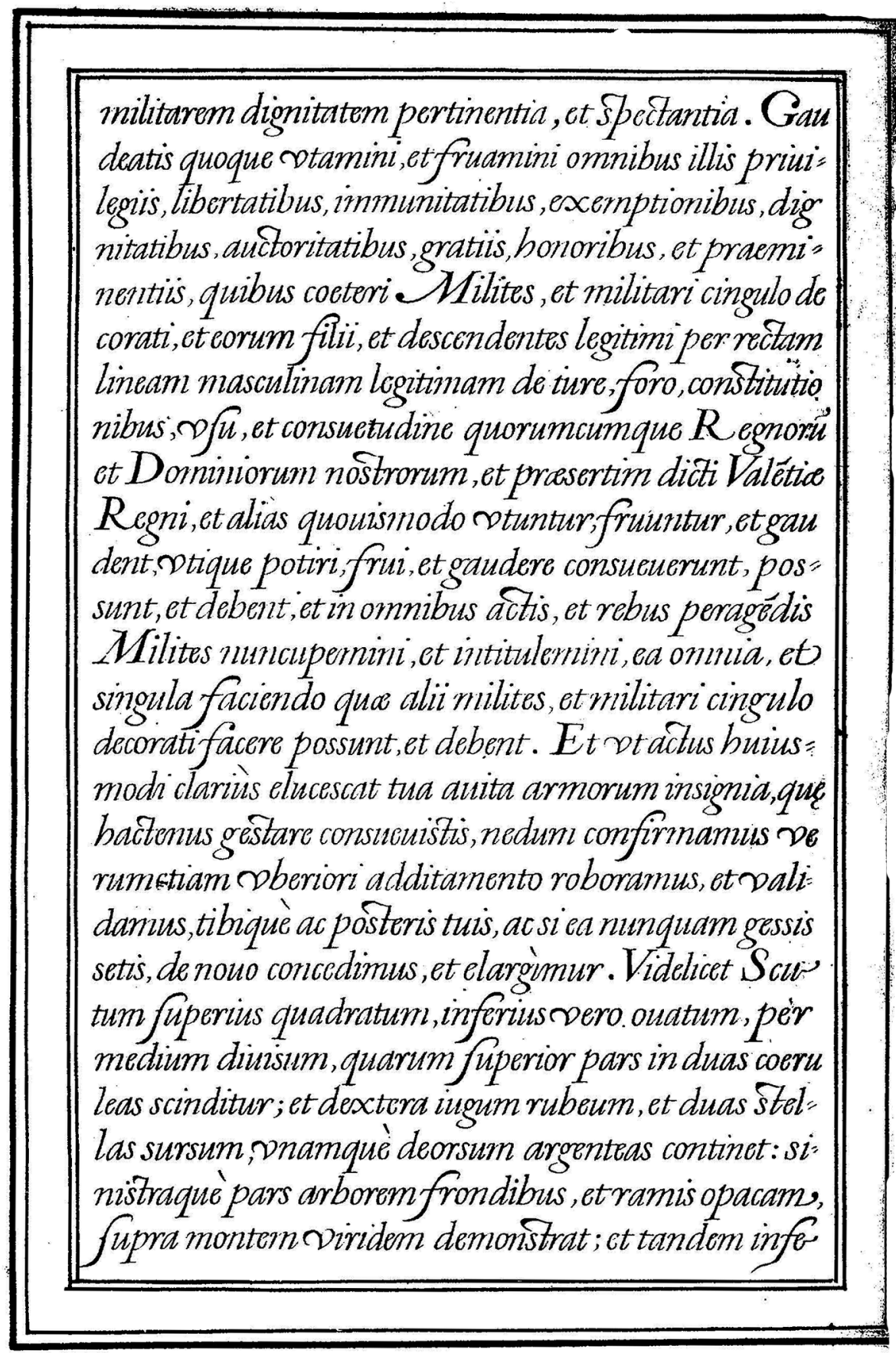




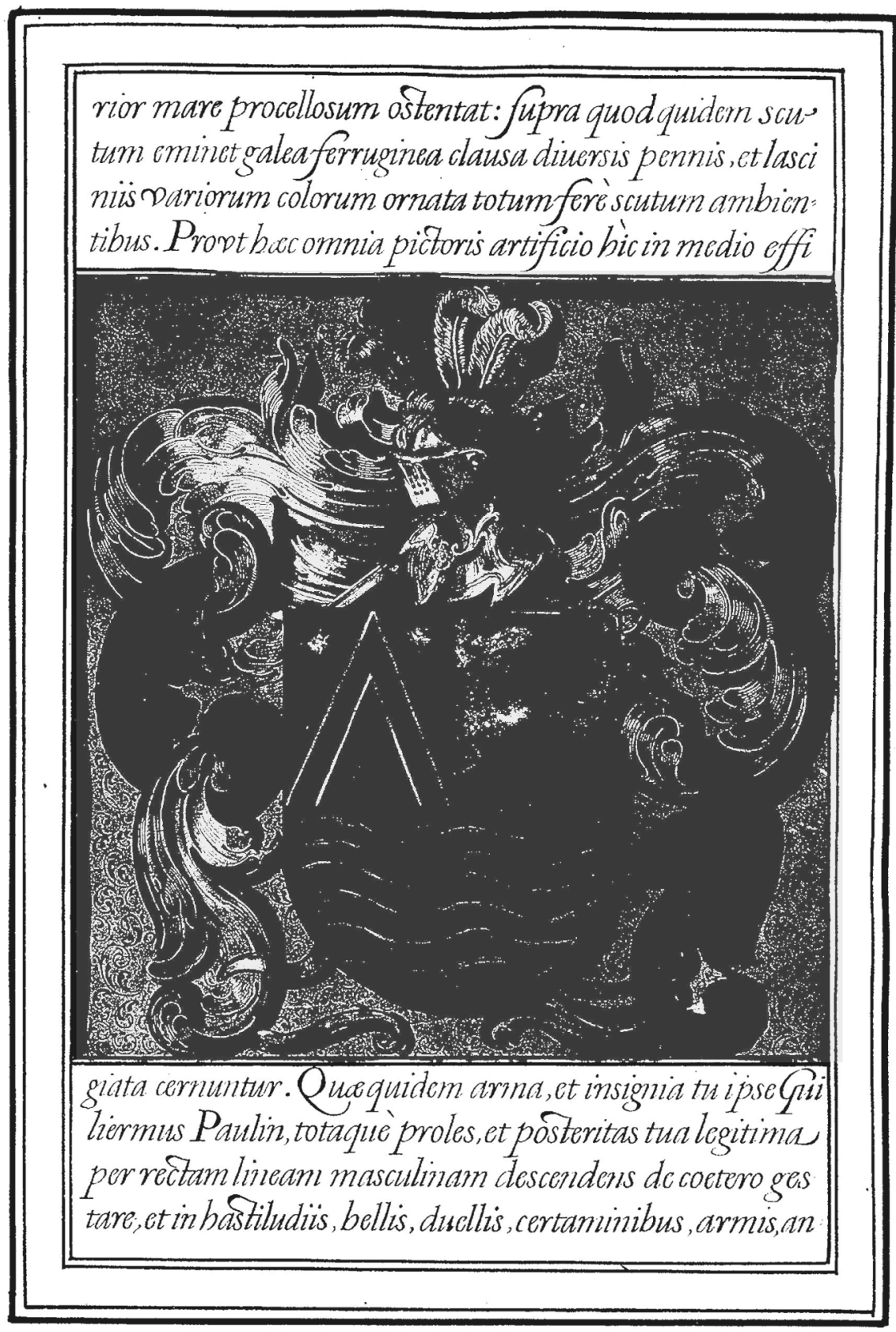


nulis, signis, sigillis, auleis, dornibius, oasis, et aliis otensili = bus, et in omnibus actis, picturis, et oedificius pro librito nolu tatis apponere, et affigere possitis, et roaleatis. Et quamois tu dictus Guiliermus Paulin ot extraneus, et alienigena iuxta foros dictivostri Valentio Regni,non possis ingredi in Curias generales, oel particulares quascum que incolis dictinostri Valentice Regni pernos, aut successores nros. celebrandas, et faciendas; attamen filiitui legitimi pers

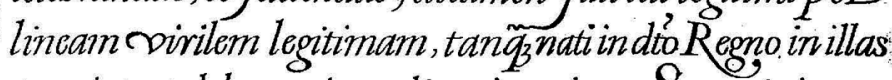
possint, et debeant ingredi, et introire. Serenissimopp terea Baltbasari Carolo Principi Áturiarum, et $\mathrm{G}_{e=}$ runda, Duciquè Calabrice, et Montisalbi, Filio Primo genito nostro charissimo, ac post foelices, et longauos dier-s nostros in omnibus Regnis, at Dominius nostris Deopro pitio immediato boeredi, et legitimo fuccessori, intentum aperientes nostrum sub paterno benedictionis obtentu di cimus eumquè rogamus. Admodumororo Ill $i$.Duci, Illiatribus, Egregiis, Spectabilibus, Veneg. Sobribus, Magnificis, Dilectisque Consiliariis, et Fidelibus nostris oniuersis, et singulis premissorum, $R$ gonorum, Domini orum, ct Derrarum nostrarum, Viceregibus, Locumtene: tibus, et Capitaneis generalib, nostris, Gerentibusquè vices nostrigeneralis $G$ ubermatoris, sen officum $R$ egentib, et quibusuis alius officialibus, et subditis nostris tam maiorib, quam minoribus cuiusuis dignitatis, Status, gradus, promi nentice, et conditionis ex cistentibus prosentibus, et futuri-6, 


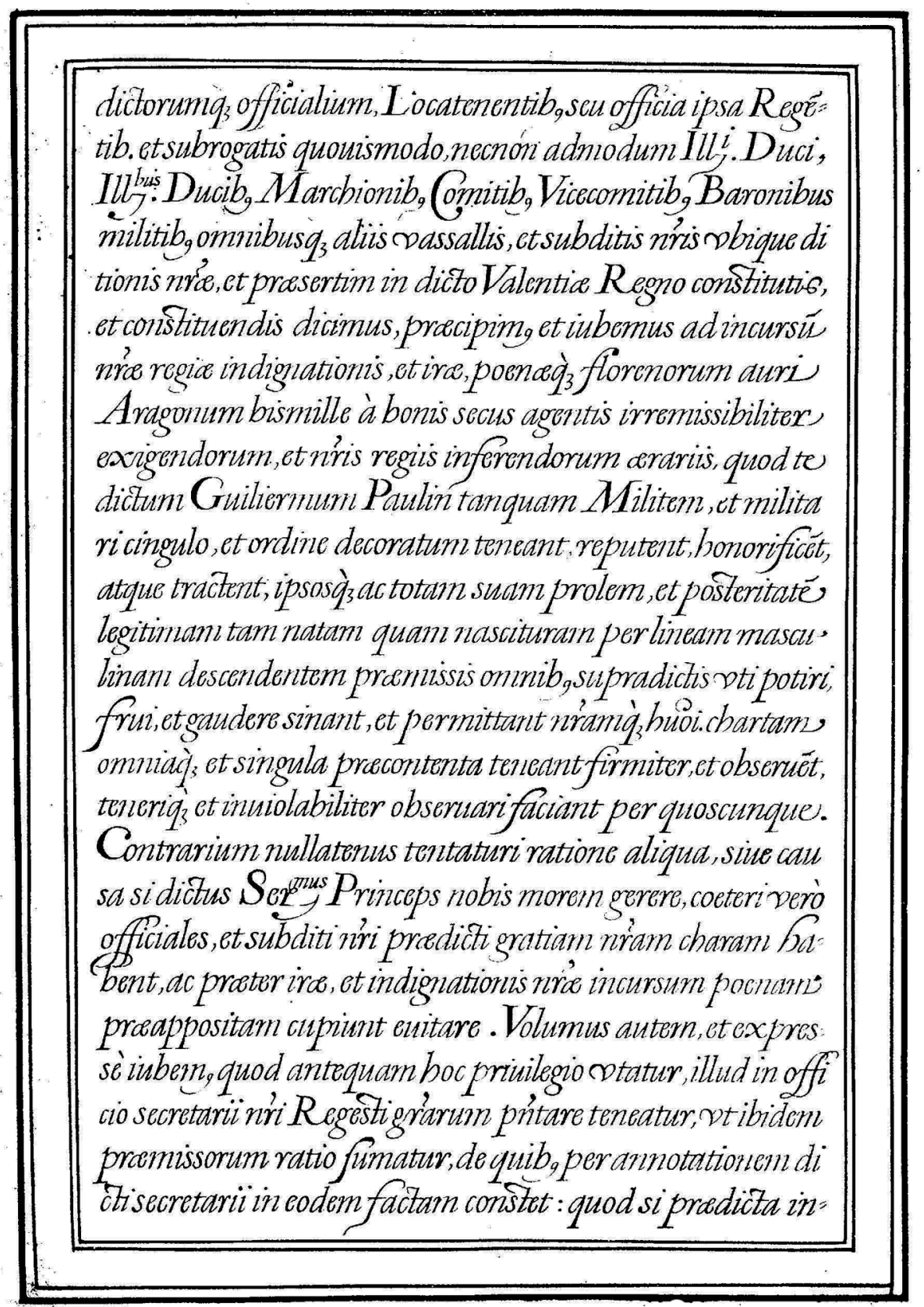




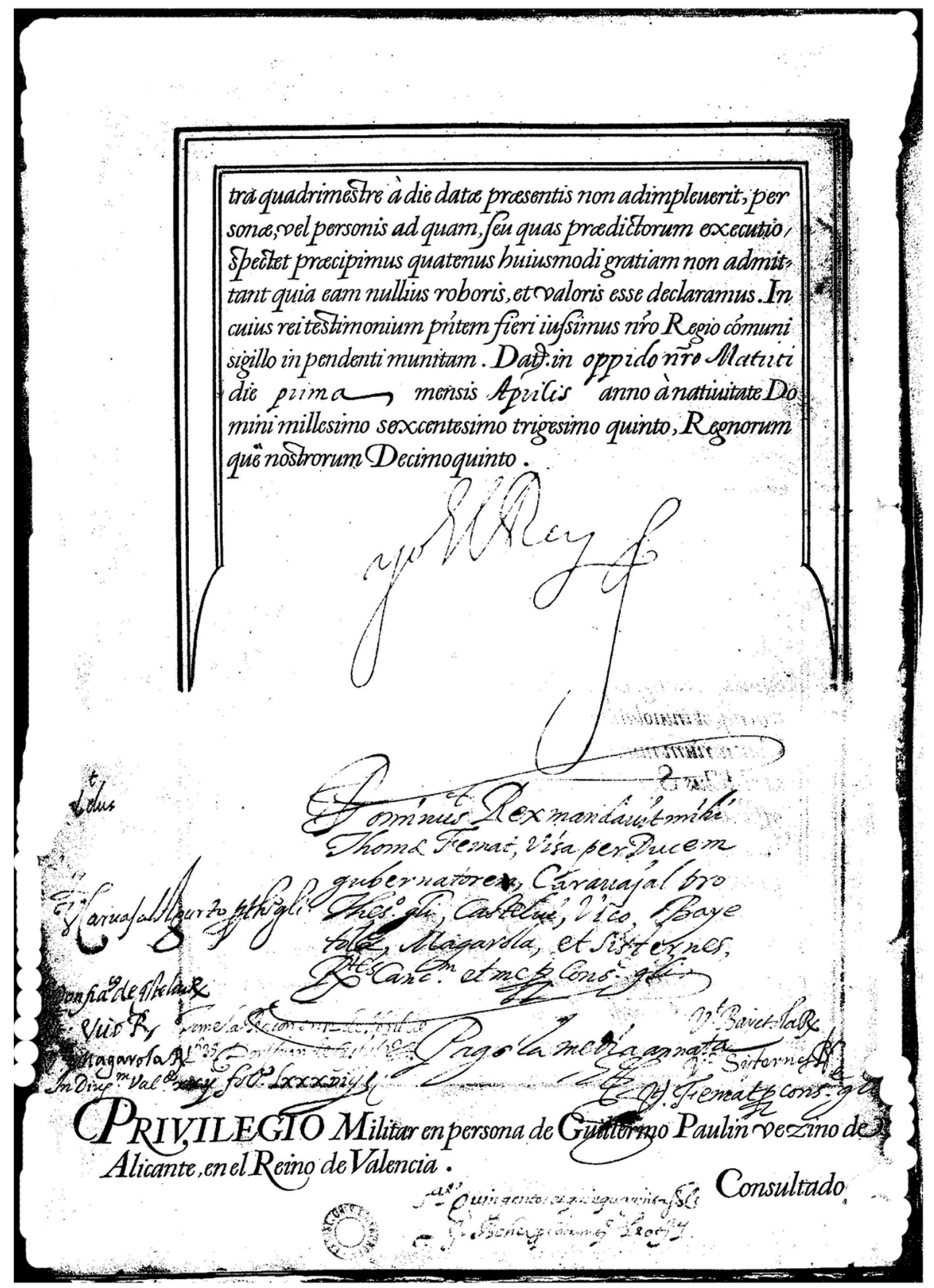


en plena Guerra de Sucesión española, en su situación de exiliado, fuera un paso precipitado. La red de parientes con que podía contar era escasa en Cartagena (sus hijos y su cuñado Juan Bautista Ansaldo, a cuya hija dejó una donación), predominando otros parientes de Génova: los Cárrega de Juan Bautista, César Colombo, presbítero, y Ana $\mathrm{M}^{\mathrm{a}}$ Oneto, sus sobrinos; y los amigos austracistas de Barcelona (Pablo Dalmases, marqués de Villalonga, y Juan Catá) ${ }^{22}$; a diferencia de la de Fulgencio Panés, que pudo apoyarse en los parientes suyos y de Juan Andrés Panés, su hermano, más numerosos (sus sobrinos Hilario y Pantaleón Lardón y Pedro Arecio, la viuda de su tío Pedro Francisco Rato, su prima Clara Mucio ${ }^{23}$.

La opción política de Juan Bautista Montanaro, que le permitió obtener un título nobiliario y fundar un mayorazgo, fue sin embargo la que también le obligó al exilio. Aunque una parte de sus hijos fueron recibidos en el bando contrario al suyo, el borbónico, recuperando parte de sus bienes, el mayorazgo quedó invalidado durante cuarenta años, de tal forma que ellos no compartieron el fugaz ascenso social de su padre. Una situación tal sólo se explica en una coyuntura convulsa, o muy peculiar, la de la Guerra de Sucesión española, pero imposible para lograr una continuidad. Por contraste, Francisco Montenegro, su cuñado, destacó por sus servicios militares a Felipe V, como en la recuperación de Orihuela, por lo que fue nombrado coronel (fue teniente general de artillería de Cartagena y juez conservador de la nación francesa. Su empleo de coronel fue anterior a la toma de Orihuela, de modo que debió tomar las armas poco después de la caída de Cartagena; tuvo una posición proborbónica desde primera hora, quizás también por rivalidades interfamiliares), y aunque pidió un título nobiliario no se le concedió (Muñoz, 2006), pero consiguió obtener la sucesión al señorío de Cúllar-Baza y a uno de los dos mayorazgos fundados por Juan Bautista Prebe.

Por lo tanto, consecución de título nobiliario y fundación de un mayorazgo se podrían considerar, en este caso de Montanaro, como concreciones de una promoción social, pero también de una práctica política, de una materialización de relación servicial, de una lealtad en el ámbito del austracismo que no deja de ser ilustrativa de otras muchas situaciones parecidas, pues la Guerra de Sucesión sirvió para concretar estrategias de promoción social iniciadas tiempo atrás.

\section{BIBLIOGRAFÍA}

ARQUES JOVER, A. (1966) [1678]: Nobiliario alicantino, Alicante, Ayuntamiento, 182 p.

BERNABÉ GIL, D. (2006): "El patrimonio de los marqueses de Rafal (1639-1736)", Revista de Historia Moderna, 24, 253-304.

CACHÓN RODRÍGUEZ, L. (1989): ¿Movilidad social o trayectoria de clase?, Madrid, 624 p.

CATALÁ SANZ, J.A. (1995): Rentas y patrimonios de la nobleza valenciana en el siglo XVIII, Madrid, Siglo XXI, 374 p.

CATALÁ SANZ, J.A. (2011): "Integridad patrimonial, perpetuidad, memoria. Contradicciones de los mayorazgos valencianos en época moderna", Studia Historica, Historia Moderna, 33, 61-95.

CHACÓN JIMÉNEZ, F. (1982): "El problema de la convivencia. Granadinos, mudéjares y cristianosviejos en el Reino de Murcia. 1609-1614”, Melanges de la Casa de Velázquez, XVIII/1, 103-133.

22 Debía tener relación con los Merano, comerciantes genoveses de Cartagena, pues unos años después hizo testamento en Murcia Plácida Ansaldo, hija de Nicolás Ansaldo y Verónica Cárrega y viuda de Juan Antonio Merano, que declaró que había perdido todos sus bienes gananciales en la revolución que sufrió Cartagena (refiriéndose a la ocupación inglesa de 1706): AHPM, Not. 2751, f. 160.

23 AHPM, Not. 1821, folios 29-47, 12-2-1686. 
CHACÓN JIMÉNEZ, F. (1995): "Hacia una nueva definición de la estructura social en la España del Antiguo Régimen a través de la familia y las relaciones de parentesco", Historia Social, 21, 75-104.

FELIPO ORTS, A. (2014): "Patrimonio familiar e infortunios financieros del linaje de los Castellví durante el siglo XVII", Studia Histórica Historia Moderna, 36, 263-292.

FELIPO ORTS, A. (2009): "Anotaciones sobre la conformación del patrimonio de don José de Castellví, marqués de Villatorcas (1653-1722)”, Saitabi, 59, 171-190.

FELIPO ORTS, A./PÉREZ APARICIO, C. (2014): La nobleza valenciana en la Edad Moderna. Patrimonio, poder y cultura, Valencia, Universitat de València, 564 p.

FERRÁNDIZ ARAUJO, C. (1981): Historia del Hospital de Caridad de Cartagena (1693-1900), Cartagena, $286 \mathrm{p}$.

GIMÉNEZ LÓPEZ, E. (1986): "La burguesía mercantil y la propiedad en el siglo XVIII. El caso de Alicante", en La ilustración española, Alicante, Instituto Juan Gil-Albert, 477-496.

GIRÓN PASCUAL, R.M. (2007): "Los señores de Cúllar en la Edad Moderna: de los Digueri a los Robles Montenegro", en Andújar Martínez, F. (ed.), Los señoríos en la Andalucía moderna. El marquesado de los Vélez, Almería, Diputación Provl., 563-572.

GIRÓN PASCUAL, R.M. (2012): Las Indias de Génova. Mercaderes genoveses en el Reino de Granada durante la Edad Moderna, Tesis Doctoral, Universidad de Granada, 425 p.

GUERRERO ARJONA, M. (2003): "Los desplazamientos moriscos provocados por la Guerra de las Alpujarras: la familia de los Arráez y sus dificultades para integrarse en la sociedad lorquina", Clavis, 3, 169-188.

GUILLAMÓN ÁLVAREZ, F.J.; MUÑOZ RODRÍGUEZ, J.D. (2006): "La lealtad castellana en la Guerra de Sucesión. Movilización social y representación del poder en una sociedad en guerra", Revista de Historia Moderna, 24, 513-536.

HENAREJOS LÓPEZ, J.F. (2013): "Del comercio a la oligarquía local y el ennoblecimiento pasando por el control del territorio o parentesco. Alianza y familia en la España del Antiguo Régimen: el caso de los Montanaro-Aguado", en Construyendo historia. Estudios en torno a Juan Luis Castellano, Granada, Universidad de Granada, 141-157.

HERNÁNDEZ FRANCO, J.; PEÑAFIEL RAMÓN, A. (1998): "Parentesco, linaje y mayorazgo en una ciudad mediterránea: Murcia (siglos XV-XVIII)", Hispania: Revista Española de Historia, 198, 157-183.

JUAN VIDAL, J. (2014): "El austracismo en el Reino de Mallorca”, Cuadernos Dieciochistas, 15, 165-193.

MAESTRE DE SAN JUAN PELEGRÍN, F. (2011): "La aristocracia de Cartagena en el siglo XVIII", Murgetana, 125, 103-126.

MARZAL RODRÍGUEZ, P. (1996): "Una visión jurídica de los mayorazgos valencianos entre la época foral y la nueva planta", Anuario de Historia del Derecho Español, 66, 229-364.

MONTANER ALONSO, P. y otros (2006): La Guerra de Succesió a Mallorca, 1700-1715, Palma, Ajuntament de Palma, $239 \mathrm{p}$.

MONTER JANER, N. (17??): Memorial ajustado del pleito pendiente en la Real Audiencia de Cataluña entre D. Ignacio de Dou y Bassols de una y Don Francisco de Milans de otra, Barcelona, Sastres, $422 \mathrm{p}$.

MONTOJO MONTOJO, V. (1991): "Matrimonio y patrimonio en la oligarquía de Cartagena (ss. XVIXVII)”, en Chacón Jiménez, F., Hernández Franco, J., Peñafiel Ramón, A. (eds.), Familia, grupos sociales y mujer en España (ss. XV-XIX), Murcia, Universidad de Murcia, 49-94.

MONTOJO MONTOJO, V. (1993): "Señorialización y remodelación jurisdiccional y económica en el Reino de Murcia: los señoríos de Hoya Morena y Cúllar-Baza (s. XVII)”, en Sarasa Sánchez, E., Serrano Martín, E. (eds.), Señorío y feudalismo en la Península Ibérica, Zaragoza, Institución Fernando el Católico, II, 457-473.

MONTOJO MONTOJO, V.; MAESTRE DE SAN JUAN PELEGRÍN, F. (1999): La Cofradía de Nuestro Padre Jesús Nazareno (Marrajos) de Cartagena en los siglos XVII y XVIII, Cartagena, Cofradía Marraja, 168 p. 
MONTOJO MONTOJO, V.; MAESTRE DE SAN JUAN PELEGRÍN, F. (2000): "La actividad de los mercaderes de Cartagena en el Reino de Granada a finales del siglo XVII", en Sánchez Ramos, V. (ed.), El Reino de Granada en el siglo XVII, Almería, Instituto de Estudios Almerienses, 111-120.

MONTOJO MONTOJO, V.; MAESTRE DE SAN JUAN PELEGRÍN, F. (2005a): "Relaciones sociales y actividades económicas de los comerciantes procedentes de los Pirineos franceses en Cartagena (España) a lo largo del siglo XVIII", en Minovez, J.-M., Poujade, P. (eds.), Circulation des marchandises et réseaux commerciaux dans les Pyrénées, Toulouse, CNRS-Université de Toulouse-Le Mirail, 191-211.

MONTOJO MONTOJO, V.; MAESTRE DE SAN JUAN PELEGRÍN, F. (2005b): "Le Béarn et le Levant espagnol", Revue de Páu et du Bearn, 32, 215-228.

MONTOJO MONTOJO, V. (2006): "El comercio de Levante durante el valimiento del Conde Duque de Olivares (1622-1643)", Revista de Historia Moderna, 24, 459-486.

MONTOJO MONTOJO, V. (2010): "Inmigration et groupes de pouvoir dans le Levant espagnol", Liens de sang, liens de pouvoir. Les élites dirigeantes urbaines dans l'Europe occidentale et dans les colonies européennes (fin XVe-fin XIXe siècles), Laurent Coste dir., Rennes, Presses universitaires de Rennes, 95-108.

MUÑOZ RODRÍGUEZ, J.D. (2003 a): “Con plausible ejemplo y finísima actividad. La movilización de una ciudad castellana en socorro de la monarquía católica: Lorca, 1688”, Clavis, 3, 189-198.

MUÑOZ RODRÍGUEZ, J.D. (2003b): Damus ut des. Los servicios de la ciudad de Murcia a la Corona a finales del siglo XVII, Murcia, Academia Alfonso X el Sabio, 303 p.

MUÑOZ RODRÍGUEZ, J.D. (2006): “`Cartagena por el Archiduque Carlos! La sublevación austracista de una ciudad castellana durante la Guerra de Sucesión”, Cartagena Histórica, 16, 27-43.

MUÑOZ RODRÍGUEZ, J.D. (2014): La séptima corona. El Reino de Murcia y la construcción de la lealtad castellana en la Guerra de Sucesión (1680-1725), Murcia, EDITUM, 490 p.

ORTEGA, P.M. (1994 [1752]): Descripción corográfica, Murcia, Real Academia Alfonso X el Sabio, $361 \mathrm{p}$.

PÉREZ APARICIO, C. (2002): "Una vida al servicio de la Casa de Austria. Don José Folc de Cardona y Erill, príncipe de Cardona (1651-1729)", Estudis, 28, 421-448.

POITRENEAU, A. (1976): "La inmigración francesa en el Reino de Valencia (ss. XVI-XIX)", Moneda y Crédito, 137, 103-133.

PRADELLS NADAL, J. (1984): Del foralismo al centralismo Alicante 1700-1725. Alicante, 290 p.

ROGLES HERNÁNDEZ, M.A. (1984): "La inmigración en Alicante (1650-1799)", Revista de Historia Moderna, 4, 387-406.

RUBIO PAREDES, J.M. (1977): Nicolás Montanaro. Observaciones sobre Antigüedades de Cartagena, Cartagena, $258 \mathrm{p}$.

RUIZ IBÁÑEZ, J.J. (2005 a): "Entre Dios y los hombres: los refugios políticos en la Alta Edad Moderna Europea”, en González Jiménez, M., et al. Acogidos y rechazados en la Historia, Valladolid, Universidad de Valladolid, 35-84.

RUIZ IBÁÑEZ, J.J. (2005b): "Bellum omnium contra omnes. Las posibilidades y contradicciones de la guerra económica por parte de la monarquía hispánica en la década de 1590”, Studia Historica Historia Moderna, 27, 85-109.

SÁNCHEZ BELÉN, J.A. (2000): "Las relaciones internacionales de la Monarquía Hispánica durante la Regencia de doña Mariana de Austria", Studia Historica Historia Moderna, 20, 137-172.

SANTARRUFINA, R. (2014): "Los Próxita. Un linaje de origen napolitano en el reino de Valencia", Estudis. Revista de Historia Moderna, 40, 237-254.

SANZ AYÁN, C. (2002): "Consolidación y destrucción de patrimonios financieros en la Edad Moderna: Los Cortizos (1630-1715)", en Fortuna y negocios de los grandes patrimonios (ss. XVI$X X)$, Ricardo Robledo, Hilario Casado eds., Valladolid, 73-98.

TORRES SÁNCHEZ, R. (1998): Ciudad y población: El desarrollo demográfico de Cartagena durante la Edad Moderna, Cartagena: Ayuntamiento de Cartagena, Real Academia Alfonso X el Sabio, 317 p. 